\title{
DIET AND THROMBUS FORMATION: QUANTITATIVE STUDIES USING AN EXTRACORPOREAL CIRCULATION IN PIGS *
}

\author{
By J. F. MUSTARD, † H. C. ROWSELL, E. A. MURPHY,
}

(From the Department of Physiological Sciences, Ontario Veterinary College, Guelph; the Blood and Vascular Disease Research Unit, Department of Medicine, University of Toronto; and Sunnybrook Hospital, Department of Veterans Affairs, Toronto, Ont.)

(Submitted for publication April 25, 1963 ; accepted July 29, 1963)

Although there has been widespread interest in the relationship of diet to atherosclerosis and its complications, much less attention has been paid to the effect of diet on thrombus formation. For the most part, exploration of this problem has been indirect; in the first place, it has been supposed that in vitro tests of coagulation are good measures of the coagulant activity of the blood and thrombus formation; and in the second, it has been supposed that coagulant activity in vivo reflects tendency to form thrombi. In a previous study (1), we attempted to circumvent the former supposition by directing our attention to platelet survival, which can be studied in vivo in man and in experimental animals. The ideal method of obviating the latter supposition would be to devise methods of quantitating thrombus formation in the intact animal. Semiquantitative grading systems have been used by some investigators. As yet, however, no satisfactory, precise quantitative method has been devised.

Connor and Poole (2) and Connor (3), recognizing that movement of the blood, particularly in the arterial circulation, may be an important factor in thrombus formation, used Chandler's apparatus (4) to study the effect of various fatty acids on thrombus formation. In their experiments, citrated blood was mixed with the fatty acid for one minute. It was then recalcified inside the apparatus, and the time for the appearance of clotting was noted.

We have described elsewhere a method for quan-

\footnotetext{
* Supported by U. S. Public Health Service grants H-4964 and H-6951 from the National Institutes of Health, and by the Armour Pharmaceutical Company. † Senior Research Associate, Canadian Heart Foundation.

¥ Present address: The Joseph Earle Moore Clinic, Johns Hopkins Hospital, Baltimore 5, Md.
}

titating thrombus formation in an extracorporeal circulation in the pig (5). Although providing information complementary to that given by other methods, our technique has these advantages: 1 ) it allows precise quantitation and 2) continual recirculation of the blood through the body, 3) the flow is pulsatile, and 4) the thrombi are formed on a surface.

A number of studies suggest that diet affects blood coagulation in both acute $(6,7)$ and longerterm studies (1). There is evidence from animal studies (8-11) and in man from epidemiological sources (12-14) that dietary fat influences thrombosis and the complications of vascular disease. So far there have been no quantitative reports published concerning the effects of dietary manipulations on thrombus formation in flowing blood in the arterial circulation.

The value of studying the acute effects of an unfamiliar diet on thrombus formation is limited. It seems likely that such a challenge might produce qualitatively different results from one giving the experimental animals a diet to which they were metabolically and psychologically habituated. An experiment has, therefore, been undertaken in four groups of pigs. Each group was given a different diet, which was continued unchanged for at least ten months.

\section{MATERIALS AND METHODS}

Animals. Thirty-two crossed Yorkshire-Landrace pigs were randomly allocated to four groups, two female and six castrated male pigs in each. Each group was given one of the four diets listed below. At the beginning of the experiment, all pigs were 4 months old. On the same day, at the tenth month of the experiment (i.e., when the pigs were 14 months old), four pigs, one chosen at random from each of the groups, were subjected to flowchamber experiments and then killed. Each month, again one pig from each group was used. The last four 
pigs were studied when they were 20 months old (i.e., 16 months after the start of the experiment). The animals were not fed on the morning of the flow-chamber experiments, their last meal having been given late in the previous afternoon.

Diets. All pigs received isocaloric diets. The control group (C) received a standard pig ration; ${ }^{1}$ a second group (E) received the same diet with $25 \%$ of the calories replaced by uncooked egg yolk; a third group (L) received the same diet as the controls, but with $25 \%$ of the calories replaced by lard; and the last group (LC) received the same diet as the $\mathrm{L}$ group with cholesterol added to the lard in an amount equal to that contained in diet $\mathrm{E}$ (Table I). After the lard was melted, the cholesterol was added to it. The animals gained weight in uniform manner. Their mean weights at the end of the study were as follows: Group C, 540 pounds; Group L, 592 pounds; Group LC, 553 pounds; and Group E, 554 pounds.

The extracorporeal shunt. The method has been described in detail elsewhere (5). In brief, it consists of measuring the dry weight of deposit formed under standard conditions in a standard, silicone-coated, precision-built plastic flow chamber in 20 minutes. Two flow chambers of the same design and dimensions, allocated at random for each study among the four groups, were used throughout.

Coagulation tests. A blood sample for clotting tests was taken from the arterial cannula just before each flow-chamber experiment. The following coagulation tests were carried out by methods which have been described (15): the whole-blood clotting time in glass and

1 The composition of this ration was as follows: fish meal, feeding tankage, blood meal, soya-bean-oil meal, corn-gluten meal, wheat shorts, calcium carbonate, bone meal, salt $\frac{1}{2} \%$, calcium iodate, copper carbonate, cobalt carbonate, iron carbonate, manganese sulfate, zinc oxide, alfalfa-grass meal, dehydrated alfalfa meal, riboflavin, vitamin $\mathrm{A}, \mathrm{D}$-activated plant sterol, vitamin $\mathrm{B}^{12}$, stabilized animal fat, and barley oats (protein $16 \%$, fats $3 \%$, fiber $8 \%$, carbohydrate $73 \%$ ). Supplied by Canada Packers, Ltd., Toronto, Ont. in silicone-coated glass tubes, the prothrombin time, the p'atelet count, the plasma thromboplastin time, and the platelet adhesive index.

Serum lipids. The serum cholesterol was determined at the beginning of each experiment by a modification of the Sperry-Schoenheimer method (16), and the serum phospholipid by the method of Zilversmit and Davis (17). FFA were determined by the method of Dole (18). The serum lipoproteins were determined by the method of Gofman (19) and his associates. ${ }^{2}$

Statistical considerations. We previously reported that the weight of deposit in the flow chamber has a lognormal distribution (20). Whole-blood clotting time is also lognormally distributed, and p!asma thromboplastin time has a harmonic normal distribution. The other clotting tests are all approximately normal in distribution (15). The appropriate normalizing transformations were used before the data were processed, but mean values were retransformed into the original scale before being inserted in the tables.

Blood cholesterol and phospholipid were lognormally distributed-these findings agree with those of several other studies. FFA showed little departure from normality. Whereas the distribution of the lipoprotein fraction $S_{\mathrm{f}} 0$ to 12 showed little skewness, there was an increase in the variance with the mean; logarithmic transformations corrected this with little change in symmetry. The values $S_{f} 12$ to 20 were left unchanged. The lipoprotein fractions $S_{\mathrm{f}} 20$ to 100 and $S_{\mathrm{f}} 100$ to 400 were so abnormal that nonparametric methods were used for analysis. Simple arithmetic means, however, were used as measures of central tendency.

Multiple comparisons among the groups have been made with linear contrasts (21). We had intended that all such contrasts should be orthogonal so that the levels of significance would be independent, but one animal died in each of two groups before the experiment could be completed, and some of the results for them, accordingly, were not available. The resulting departure from orthogonality has proved unimportant. It will be evi-

2 At the Ultracentrifuge Laboratory, McGill University, Montreal, Que.

TABLE I

Diets for experimental pigs

\begin{tabular}{|c|c|c|c|c|c|}
\hline \multirow[b]{2}{*}{ Group* } & \multirow[b]{2}{*}{ Composition } & \multicolumn{4}{|c|}{ Estimated content } \\
\hline & & Protein & Carbohydrate & Fat & Cholesterol \\
\hline & & \multicolumn{4}{|c|}{$\%$ total wt } \\
\hline $\mathrm{C}$ & Hog grower ration & 16 & 73 & 3 & 0 \\
\hline $\mathrm{L} \dagger$ & Hog grower ration, $25 \%$ of calories replaced by lard & 12 & 68.5 & 11.5 & 0.01 \\
\hline $\mathrm{E}$ & Hog grower ration, $25 \%$ of calories replaced by egg yolk & 16.1 & 68 & 7.3 & 0.468 \\
\hline $\mathrm{I} . \mathrm{C} \dagger$ & $\begin{array}{l}\text { Hog grower ration, } 25 \% \text { of calories replaced by lard and an amount of } \\
\text { cholesterol equal to that in the egg-yolk diet }\end{array}$ & 12 & 68 & 11.5 & 0.468 \\
\hline
\end{tabular}

* Group C, control; L, lard; E, egg yolk; LC, lard plus added cholesterol.

$\dagger$ Lard and cholesterol were supplied by Lever Brothers, Toronto, Ont. The cholesterol was purified cholesterol, technical grade. 
TABLE II

Diet and weight of thrombus formed with analysis of variance of weights of deposits*

\begin{tabular}{|c|c|c|c|c|c|c|c|}
\hline & & \multicolumn{6}{|c|}{ Group } \\
\hline & & $\mathrm{C}$ & \multicolumn{2}{|c|}{$\mathrm{L}$} & \multicolumn{2}{|l|}{ LC } & $\mathrm{E}$ \\
\hline \multicolumn{2}{|c|}{$\begin{array}{l}\text { Geometric mean wt of } \\
\text { deposit }\end{array}$} & $\begin{array}{c}m g \\
0.144[7]\end{array}$ & \multicolumn{2}{|c|}{$\begin{array}{c}m g \\
1.042[7]\end{array}$} & \multicolumn{2}{|c|}{$\begin{array}{c}m g \\
1.069[8] \quad 3\end{array}$} & $\begin{array}{c}m g \\
3.224[8]\end{array}$ \\
\hline Source & $\begin{array}{l}\text { Degree } \\
\text { of } \\
\text { freedon }\end{array}$ & $\begin{array}{l}\text { Sum } \\
\text { squar }\end{array}$ & & & $\begin{array}{l}\text { Mean } \\
\text { quare }\end{array}$ & $\mathrm{F}$ & $\mathrm{p}$ \\
\hline Treatments & 3 & 6.9580 & 016 & 2.319 & 9339 & 2.63 & $<0.1$ \\
\hline$C \vee s \mathrm{~L}, \mathrm{LC} \& \mathrm{E}$ & 1 & 5.6 & 47541 & & .647541 & 6.40 & $<0.02$ \\
\hline E vs $\mathrm{L} \& \mathrm{LC}$ & 1 & 1.22 & 24411 & & .224411 & 1.39 & $<0.25$ \\
\hline L vs $\mathrm{LC}$ & 1 & 0.00 & 00462 & & .000462 & 0.00 & $<1.0$ \\
\hline Error & 26 & 22.9437 & 732 & 0.88 & 2451 & & \\
\hline Total & 29 & 29.9017 & 748 & & & & \\
\hline
\end{tabular}

* See methods for account of unequal number of experimental animals. Numbers in brackets indicate the number of animals observed. For explanation of abbreviations, see footnote to Table I.

dent that the sums of the contrast sums of squares is less than the total sum of squares among the treatments, so that ignoring nonorthogonality would lead, if anything, to an underestimate of the differences between the sets of treatments. The following contrasts seemed to be appropriate: 1) control versus fat-fed animals, 2) egg yoik versus other fat-fed, and 3) lard versus lard plus added cholesterol. This set of contrasts exhausts the treatment sums of squares, and no further contrasts can propcrly be done.

\section{RESULTS}

Weights of thrombi. Geometric mean weights with the analysis of variance are shown in Table II. ${ }^{3}$ If all the results are pooled, there is no significant difference among them. If, however, the control animals are compared with the three fatfed groups, the difference is significant at the one-in-fifty level. The lard and lard-cholesterol groups showed virtually identical results; eggyolk diets produced somewhat heavier deposits than in the pooled lard and lard-cholesterol groups, but this difference may easily have arisen by chance. For such contrasts to be legitimate, they must be decided upon before the data are available. Therefore, in spite of the biggest dif-

3 To obviate bias the pigs were chosen at random, without regard to sex and length of time on the diets. When these effects were analyzed, a complex process because of the two missing values, they were found to be no greater than the error mean square. In the interests of simplicity and in order to conserve error degrees of freedom, the results were treated as if they were obtained in an experiment performed completely at random. ference being between pigs fed egg yolk and the control diet, this contrast would not be proper.

In vitro tests of coagulation. A summary of the results is presented in Table III, including the appropriate mean values and a summary of the analyses of variance. Note that the values obtained are unimpressive, with only one of them significant at the $2 \%$ level or less, this being the platelet adhesive index for the controls versus the other groups.

Serum lipid values. A summary of the restits for the serum cholesterol, phospholipid, and FFA is given in Table IV. The results do not show significant differences between FFA values. The cholesterol values are higher in the fat-fed animals than in the controls, and among the fat-fe 1 animals, there is a conspicuous difference between the lard and lard-cholesterol groups. The phospholipid values show similar but less marked differences.

TABLE III

Diet and in vitro tests of clotting with summary of analyses of variance*

\begin{tabular}{|c|c|c|c|c|c|c|}
\hline \multirow{2}{*}{ Tests $\dagger$} & & \multicolumn{5}{|c|}{ Group } \\
\hline & & C & \multicolumn{2}{|l|}{$\mathrm{L}$} & LC & $\mathrm{E}$ \\
\hline \multicolumn{7}{|l|}{ Whole-blood clotting time } \\
\hline Glass, minutes & & \multirow{2}{*}{$\begin{array}{r}5.15 \ddagger[7] \\
17.70 \ddagger[7]\end{array}$} & \multicolumn{2}{|c|}{$\begin{array}{r}4.83 \ddagger \\
17.70^{\ddagger}\end{array}$} & $5.27 \ddagger$ & $5.08 \ddagger$ \\
\hline Silicone, minutes & & & 17.7 & & $3.80 \ddagger$ & $14.16 \ddagger$ \\
\hline \multicolumn{2}{|l|}{$\begin{array}{l}\text { One-stage prothrombin } \\
\text { time, seconds }\end{array}$} & $14.3 \quad[7]$ & \multicolumn{2}{|c|}{14.5} & 14.8 & 15.2 \\
\hline \multicolumn{2}{|l|}{$\begin{array}{l}\text { Plasma thromboplastin } \\
\text { time, seconds }\end{array}$} & $10.16 \S$ & \multicolumn{2}{|c|}{$10.11 \S$} & $10.31 \S$ & $9.42 \S$ \\
\hline \multicolumn{2}{|l|}{$\begin{array}{l}\text { Platelet count, no. } / \mathrm{mm}^{3} \\
\quad \times 10^{3}\end{array}$} & 227.5 & \multicolumn{2}{|c|}{292.5} & 235.0 & 277.5 \\
\hline \multirow[t]{3}{*}{ Platelet adhesive index } & & 0.99 & 1.2 & & 1.10 & 1.21 \\
\hline & \multicolumn{2}{|c|}{ Error } & \multicolumn{4}{|c|}{ F ratios } \\
\hline & $\begin{array}{l}\text { Degrees } \\
\text { of } \\
\text { freedom }\end{array}$ & $\begin{array}{l}\text { Mean } \\
\text { n square }\end{array}$ & $\begin{array}{l}\text { Treat- } \\
\text { ments }\end{array}$ & $\begin{array}{l}\mathrm{C} v \mathrm{vs} \\
\mathrm{L}, \mathrm{LC} \\
\dot{\&} \mathrm{E}\end{array}$ & $\begin{array}{l}\text { E vs } \\
\text { L \& } \\
\text { LC }\end{array}$ & $\stackrel{\mathrm{L}}{\mathrm{LC}}$ \\
\hline \multicolumn{7}{|l|}{$\begin{array}{l}\text { Whole blood clotting } \\
\text { time }\end{array}$} \\
\hline $\begin{array}{l}\text { Glass } \\
\text { Silicone }\end{array}$ & 27 & 0.01729 & 0.115 & 0.019 & 0.003 & $\begin{array}{ll}3 & 0.323\end{array}$ \\
\hline Silicone & 27 & 0.03933 & 0.694 & 0.644 & 0.251 & $1 \quad 1.186$ \\
\hline $\begin{array}{l}\text { One-stage } \\
\text { prothrombin time }\end{array}$ & 27 & 5.4447 & 0.235 & 0.330 & 0.338 & $\begin{array}{ll}3 & 0.037\end{array}$ \\
\hline $\begin{array}{l}\text { Plasma thrombo- } \\
\text { plastin time }\end{array}$ & 28 & 3.07696 & 0.433 & 0.099 & 1.153 & $3 \quad 0.045$ \\
\hline Platelet count & 28 & $5,566.07$ & 1.452 & 1.797 & 0.182 & 2.376 \\
\hline Platelet adhesive index & $\quad 28$ & 0.09297 & 2.697 & $6.392 \|$ & 0.563 & $\begin{array}{ll}3 & 1.137\end{array}$ \\
\hline
\end{tabular}

* Eight animals were observed in each experiment unless the number in brackets indicates otherwise. See footnote to Table I for explanain brackets indicates $t$ of abbreviations.
Data are mean values.

t Data are mean value

Geometric mean.
Harmonic mean.

$\mathrm{p}<\mathbf{0 . 0 2}$. 
TABLE IV

Diet and serum lipid with summary of analyses of variances*

\begin{tabular}{|c|c|c|c|c|c|c|}
\hline \multirow{2}{*}{\multicolumn{2}{|c|}{ Tests† }} & \multicolumn{5}{|c|}{ Group } \\
\hline & & C & $\mathbf{L}$ & \multicolumn{2}{|c|}{ LC } & $\mathrm{E}$ \\
\hline \multirow{2}{*}{\multicolumn{2}{|c|}{$\begin{array}{l}\text { Cholesterol, } m g / 100 m l \\
\text { Phospholipid, } \\
m g / 100 \mathrm{ml}\end{array}$}} & $113.2 \ddagger$ & $127.4 \ddagger$ & \multicolumn{2}{|c|}{$221.8 \ddagger$} & $151.0 \ddagger$ \\
\hline & & $106.1 \ddagger$ & $139.0 \ddagger$ & \multicolumn{2}{|c|}{$174.8 \ddagger$} & $142.0 \ddagger$ \\
\hline \multicolumn{2}{|c|}{ Free fatty acid, $m E q / L$} & $160.9[6]$ & $129.5[7]$ & \multicolumn{2}{|c|}{ ] $149.1[7]$} & $147.8[7]$ \\
\hline \multicolumn{3}{|c|}{ Error } & \multicolumn{4}{|c|}{ F ratios } \\
\hline Test & $\begin{array}{l}\text { Degrees } \\
\text { of } \\
\text { freedom }\end{array}$ & $\begin{array}{l}\text { Mean } \\
\text { square }\end{array}$ & $\begin{array}{l}\text { Treat- I } \\
\text { ments }\end{array}$ & $\begin{array}{l}\text { C vs } \\
\mathrm{L}, \mathrm{LC} \\
\& \mathrm{~L}\end{array}$ & $\begin{array}{l}\text { E vs } \\
\text { L\&\& } \\
\text { LC }\end{array}$ & $\begin{array}{l}\text { L vs } \\
\text { LC }\end{array}$ \\
\hline Cholesterol & 28 & 0.01800 & $7.233 \S 8$ & 8.1368 & 0.646 & $12.918 \S$ \\
\hline Phospholipid & 28 & 0.01746 & $3.623 \| 8$ & 8.1078 & 0.500 & 2.263 \\
\hline Free fatty acid & 23 & 23.277 & $0.474 \quad 0$ & 0.704 & 0.146 & 0.574 \\
\hline
\end{tabular}

* Footnote to Table I explains abbreviations.

Data are mean values.

$\mp$ Geometric mean. Eight animals were used in each experiment unless the number in brackets indicates otherwise.

$\left\{\begin{array}{l}\mathrm{p}<0.01 \\ \mathrm{p}<0.05\end{array}\right.$

The lipoprotein results are given in Table V. For standard $S_{\mathrm{f}}$ fractions 0 to 12 and 12 to 20 , there are significant differences among the treatments. The orthogonal contrasts locate these principally between the lard and lard-cholesterol groups. Little and Shanoff (22) have shown in man that the standard $S_{f} 20$ to 100 and 100 to 400 lipoprotein fractions are lognormally distributed; however, several readings in the present study were zero; thus we abandoned the classical analysis of variance in favor of the nonparametric

TABLE V

Diet and lipoproteins with summary of analyses of variance*

\begin{tabular}{|c|c|c|c|c|c|c|}
\hline \multirow{2}{*}{\multicolumn{2}{|c|}{$\begin{array}{l}\text { Standard } \\
\text { St values }\end{array}$}} & \multicolumn{5}{|c|}{ Group } \\
\hline & & C & $L$ & LC & $\mathrm{E}$ & \\
\hline \multicolumn{2}{|c|}{$0-12$} & $125.1 \dagger$ & $137.4 \dagger$ & $291.0 \dagger$ & \multicolumn{2}{|c|}{$178.2 \dagger$} \\
\hline \multicolumn{2}{|c|}{$12-20$} & 5.500 & 4.375 & 101.625 & \multicolumn{2}{|c|}{24.875} \\
\hline 20 & 100 & 3.375 & 2.250 & 30.125 & \multicolumn{2}{|c|}{9.875} \\
\hline \multicolumn{2}{|c|}{$100-400$} & 0.125 & 1.625 & 8.000 & 2.0 & 25 \\
\hline & \multicolumn{2}{|c|}{ Error } & \multicolumn{4}{|c|}{ F ratios } \\
\hline & $\begin{array}{l}\text { Degrees } \\
\text { of } \\
\text { freedom }\end{array}$ & $\begin{array}{l}\text { Mean } \\
\text { square }\end{array}$ & $\begin{array}{l}\text { Treat- } \\
\text { ments }\end{array}$ & $\begin{array}{l}C \text { vs } L \text {, } \\
\text { LC \& E }\end{array}$ & $\begin{array}{l}\text { Evs L } \\
\text { \& LC }\end{array}$ & $\underset{\text { LC }}{\text { L vs }}$ \\
\hline $0-12$ & 28 & 0.01704 & $12.677 \ddagger$ & $12.304 \S$ & 0.775 & $24.952 \ddagger$ \\
\hline $12-20$ & 28 & 2211.81 & $7.651 \ddagger$ & 3.943 & 1.907 & $17.104 \ddagger$ \\
\hline $20-100$ & \multicolumn{2}{|l|}{28} & \multicolumn{4}{|c|}{$x 2^{2}=10.48 \S$} \\
\hline $100-400$ & \multicolumn{2}{|l|}{28} & \multicolumn{4}{|c|}{$x 2^{2}=8.86 \|$} \\
\hline
\end{tabular}

* Each value is the mean of eight experiments expressed in $\mathrm{mg}$ pe $100 \mathrm{ml}$. Analysis of variance was performed by the nonparametric method of Kruskal and Wallis.

$t$ Geometric mean.

$\neq \mathrm{p}<0.001$.

p $<0.01$.
TABLE VI

Correlation coefficients between weight of thrombus and various blood lipids*

\begin{tabular}{lccc}
\hline \multicolumn{1}{c}{$\begin{array}{c}\text { Correlation between log wt } \\
\text { of thrombus and }\end{array}$} & r & t & p \\
\hline Standard $\mathrm{S}_{\mathrm{f}}$ 0-12 lipoproteins & 0.122 & 0.548 & 0.6 \\
Standard $\mathrm{S}_{\mathrm{f}} 12-20$ lipoproteins & 0.077 & 0.345 & 0.8 \\
Log cholesterol & 0.434 & 2.259 & 0.02 \\
Log phospholipid & 0.330 & 1.640 & 0.2 \\
Free fatty acid & 0.332 & 1.492 & 0.2
\end{tabular}

${ }^{*}$ For explanation of method see text

method of Kruskal and Wallis (23). This technique shows significant differences among the treatments for both fractions. The principal components of the treatment variance must be located by inspection; it clearly lies in the high mean values for the lard-cholesterol group, and to a lesser extent in the egg-yolk values.

Correlation between serum lipid values and thrombus formation. The correlations between the weight of thrombus, and the serum cholesterol, phospholipid, FFA, standard $\mathrm{S}_{\mathrm{f}} 0$ to 12 , and 12 to 20 lipoprotein fractions, respectively, were computed (Table VI). In each case, the covariances were computed separately for the four groups, pooled, and the variances for the two variates treated in a like fashion. The $r$ was then computed as the pooled covariance divided by the geometric mean of the pool variances, i.e.,

$$
\frac{\sum_{i} \sum_{i}\left(X_{i j}-\bar{X}_{i}\right)\left(Y_{i j}-\bar{Y}_{i}\right)}{\sqrt{\left[\sum_{i} \sum_{j}\left(X_{i j}-\bar{X}_{i}\right)^{2}\right]\left[\sum_{i} \sum_{j}\left(Y_{i j}-\bar{Y}_{i}\right)^{2}\right]}},
$$

where $\bar{Y}_{i}=\frac{1}{n^{i}} \sum_{j} Y_{i i}$, and so forth.

This method involves the estimation of eight parameters, so that eight degrees of freedom are lost. In view of the small numbers involved, we felt that the non-normality of the distribution of $S_{\mathrm{f}} 20$ to 100 and 100 to 400 precluded the use of this method for them. The serum cholesterol alone showed a significant correlation with the amount of thrombus formed.

Relationship between in vitro coagulation tests and thrombus formation. We performed covariance analyses of the weight of the deposit formed on the various clotting tests (Table VII). The pooled mean square for the regression was 
TABLE VII

Regression of clotting tests on weight of deposit

\begin{tabular}{lcc}
\hline \multicolumn{1}{c}{ Clotting test } & $\mathrm{F}$ & $\mathrm{p}$ \\
\hline Clotting time & & \\
$\quad$ Glass & 0.429 & $<0.9$ \\
$\quad$ Silicone & 1.837 & $<0.25$ \\
Platelet count & 0.950 & $<0.5$ \\
Platelet adhesive index & 1.513 & $<0.25$ \\
Prothrombin time & 1.736 & $<0.25$ \\
Plasma thromboplastin time & 2.771 & $<0.1$ \\
\hline
\end{tabular}

tested against the pooled residual mean error. None of the results was significant.

\section{DISCUSSION}

These data show that diets rich in fat influence the amount of deposit formed in an extracorporeal circulation in pigs. The principal difference in these isocaloric diets lay in their fat content with reciprocal changes in protein and carbohydrate of the basic diet. The egg-yolk diet produced the heaviest deposit; the lard and the lard with added cholesterol diets had intermediate and almost identical effects; the standard pig ration with no added fat had the least effect. The only statistically decisive difference, however, was between the values in the control group and in the three groups, taken together, with added fat. To some extent, this lack of difference among the groups reflects the way the data were analyzed, more detailed comparisons among the several groups being impossible without abandoning the principle of orthogonality among them.

One point worthy of note, however, is that there is nothing approaching a significant difference in the weights of deposits between the animals fed lard with added cholesterol and those fed only unenriched lard. This suggests that added dietary cholesterol as such has little influence on thrombus formation in the shunt system, at least in the range used in this experiment. Our experience tallies with in vitro work concerning the effect of cholesterol on blood coagulation (24). The pigs given the diet rich in egg yolk had three times as heavy a deposit as those on diets containing lard. Although this difference seems to be impressive, its importance is somewhat diminished because the weights of the deposits are lognormally distributed and the difference between them is not significant $(p<$
$0.25)$. Since the scale of the experiment was small, however, and the variation in size of deposit great, this apparent difference should be subjected to further study.

Since previous work has shown changes in coagulation tests during lipemia after the ingestion of a high-fat meal $(7,20)$, the question must be asked whether the differences found in our study are due to prolonged dietary treatment. As all the animals were examined after fasting for 16 to 20 hours, it seems unlikely that differences were due to postprandial lipemia. We do not yet know how long a period of dietary manipulation is required to produce changes in thrombus formation. Exploring this question and also determining how long the effect of a thrombogenic diet persists after it is discontinued are important tasks. We do know, however, that animals accustomed to their respective diets tend toward thrombosis. Over the ranges studied in this experiment, the duration of the diets had no demonstrable effect on the weights of deposit formed, nor were there differences in the results between the males and the females.

There is considerable evidence that dietary fat has at least an acute effect on some in vitro tests of blood coagulation $(6,7,25)$. The relationship between in vitro coagulation, endogenous coagulation, and thrombosis has been in some doubt. but we have provided evidence from studies with man involving more prolonged dietary change, notably in fat. Not only were there alterations in some in vitro tests of coagulation, but also platelet survival was shortened (1). The platelet is probably a more direct measure of endogenous coagulation, and certainly a factor involved in the early stage of thrombus formation.

Our findings relate more closely to the problem of thrombus formation, and in general agree with those from less direct studies. Unlike earlier studies, however, our present one does not show a significant relationship between the amount of deposit formed and the various blood-coagulation tests. This may be attributable to the small numbers involved, or it may indicate that the effect of diet on thrombus formation and blood coagulation is complex. The increase in thrombus formation seen with the lipid-rich diets may be related to some factor other than change in blood coagulation. These findings again caution against 
extending the conclusions of in vitro clotting tests to phenomena in the intact organism.

Serum cholesterol shows a significant positive correlation with the weight of deposit. Other evidence of this experiment seems to indicate that this cannot be interpreted to mean that high serum cholesterol causes thrombus formation. The diet of lard with added cholesterol differed frrm the lard diet only in the amount of cholesterol, which was sufficient to double the serum cholesterol, yet there was not significant difference between the two groups in the weight of deposit formed. It seems more reasonable that, for a particular diet, a high serum cholesterol and a tendency to produce an unusually heavy deposit are separate consequences of some common factor.

Although other experiments differed in method and structure, their findings $(2,3)$ agree with ours in suggesting that fats are important in thrombus formation and that some fats are more active in this respect than others. Several workers have shown in experiments on animals given thrombogenic diets that for thrombosis to occur, certain fats must be present $(9,26)$. Despite our agreement, we cannot definitely conclude that the effects we observed are entirely caused by fat. We studied rapidly flowing blood in physical, but not in physiological, isolation from the rest of the tissues. Thus, whereas the blood was influenced by the homeostatic mechanisms in the body, at the site where the thrombus was formed, there was no contribution from other vital structures. Although the silicone-coated plastic surface was foreign, it was uniformly so throughout the experiment, and there was no reason to believe that diet changed its physical properties. Thus, we can probably conclude that our results were the effects of diet on the thrombotic tendency of flowing blood.

The present experiment shows that these changes in diet produce no catastrophic effects in the tendency of blood to form thrombi, but merely augment the process seen in the control animals.

\section{SUM MARY}

Our study concerned several diets differing principally in their fat composition, some in vitro tests of coagulation, the tendency for thrombi to form in flowing blood, and some blood lipid fractions. Four isocaloric diets were used: 1) a lowfat diet, and three other diets with $25 \%$ of the calories in the basic diet replaced by 2) lard, 3) egg yolk, and 4) lard and as much added cholesterol as in the egg-yolk diet.

Significant differences were produced in the platelet adhesive index, which was higher in the pigs receiving added fat than in the control group. None of the other coagulation tests showed any significant differences.

Similar results were revealed by comparison of the weight of deposit formed in the extracorporeal shunts, a mean weight of deposit lower in the control group than in the other groups $(\mathrm{p}<$ 0.02 ), but there were no significant differences otherwise. The egg-yolk diet produced the highest mean weight of deposit. There was no difference between the mean weights of deposits for the group given lard, and that given lard plus addled cholesterol, although serum cholesterol was nearly twice as high in the latter group. For a given diet, however, there is a significant correlation $(r=+0.43, p<0.02)$ between blood cholesterol level and weight of thrombus.

Serum cholesterol, phospholipids, and lipoprotein, with almost perfect uniformity, were highest in the lard-cholesterol group, next highest in the egg-yolk group, and least in the control group.

\section{REFERENCES}

1. Mustard, J. F., and E. A. Murphy. Effect of different dietary fats on blood coagulation, platelet economy, and blood lipids. Brit. med. J. 1962, 1, 1651.

2. Connor, W. E., and J. C. F. Poole. The effect of fatty acids on the formation of thrombi. Quart. J. exp. Physiol. 1961, 46, 1.

3. Connor, W. E. The acceleration of thrombus formation by certain fatty acids. J. clin. Invest. 1962, 41, 1199.

4. Chandler, A. B. In vitro thrombotic coagulation of the blood. A method for producing a thrombus. Lab. Invest. 1958, 7, 110.

5. Downie, H. G., E. A. Murphy, H. C. Rowsell, and J. F. Mustard. Extracorporeal circulation: a device for the quantitative study of thrombus formation in flowing blood. Circulat. Res. 1963, 12, 441.

6. O'Brien, J. R. Fat ingestion, blood coagulation and atherosclerosis. Amer. J. med. Sci. 1957, 234, 373. 
7. Mustard, J. F. Platelets, thrombosis and vascular disease. Canad. med. Ass. J. 1961, 85, 621.

8. Thomas, W. A., and W. S. Hartroft. Myocardial infarction in rats fed diets containing high fat, cholesterol, thiouracil and sodium cholate. Circulation 1959, 19, 65.

9. Gresham, G. A., and A. N. Howard. The independent production of atherosclerosis and thrombosis in the rat. Brit. J. exp. Path. 1960, 41, 395.

10. Naimi, S., R. Goldstein, M. M. Nothman, G. F. Wilgram, and S. Proger. Cardiovascular lesions and changes in blood coagulation and fibrinolysis associated with diet-induced lipemia in the rat. J. clin. Invest. 1962, 41, 1708.

11. Bergentz, S. E., E. L. Gelin, and C. M. Rudenstam. Fat, thrombosis and anticoagulants. An experimental study. Nord. Med. 1961, 65, 479.

12. Malmros, H., G. Biörek, and B. Swahn. Hypertension, atherosclerosis and diet. Acta med. scand. 1956, 514, suppl. 312, 71.

13. Thomas, W. A., J. N. P. Davis, R. M. O'Neal, and A. A. Dimakulangan. Incidence of myocardial infarction correlated with venous and pulmonary thrombosis and embolism. Amer. J. Cardiol. 1960, 5, 41.

14. Briggs, R. D., M. L. Rubenberg, R. M. O'Neal, W. A. Thomas, and W. S. Hartroft. Myocardial infarction in patients treated with sippy and other high-milk diets. An autospy study of fifteen hospitals in the U. S. A. and Great Britain. Circulation 1960, 21, 538 .

15. Murphy, E. A., and J. F. Mustard. Dicumarol therapy. Some effects on platelets and their relationship to clotting tests. Circulat. Res. 1960, 8, 1187.
16. Sperry, W. M., and M. Webb. Revision of Schoenheimer-Sperry method for cholesterol determination. J. biol. Chem. 1950, 187, 97.

17. Zilversmit, D. B., and A. K. Davis. Microdetermination of plasma phospholipids by trichloracetic acid precipitation. J. Lab. clin. Med. 1950, 35, 155.

18. Dole, V. P. A relation between non-esterified fatty acids in plasma and the metabolism of glucose. J. clin. Invest. 1956, 35, 150.

19. Gofman, J. W., H. B. Jones, F. T. Lindgren, T. P. Lyon, H. A. Elliott, and B. Strisower. Blood lipids and human atherosclerosis. Circulation 1950, 2, 161.

20. Mustard, J. F., E. A. Murphy, H. C. Rowsell, and H. G. Downie. Factors influencing thrombus formation in vivo. Amer. J. Med. 1962, 33, 621.

21. Cochran, W. G., and G. M. Cox. Experimental Designs, 2nd ed. New York, John Wiley, 1957.

22. Little, J. A., and H. M. Shanoff. Serum lipids and lipoproteins in healthy adult Canadian males. Canad. med. Ass. J. 1962, 86, 1045.

23. Kruskal, W. H., and W. A. Wallis. Use of ranks in one criterion variance analysis. J. Amer. statist. Ass. 1952, 47, 525.

24. Robinson, D. S. Chemical composition of chylomicra in rat. Quart. J. exp. Physiol. 1955, 40, 112.

25. Schmidt, J., and G. O. Clifford. Influence of fat on blood coagulation: its detection with a modified thromboplastin generation test. J. Lab. clin. Med. 1962, 59, 327.

26. Thomas, W. A., W. S. Hartroft, and R. M. O'Neal. Modification of diets responsible for induction of coronary thromboses and myocardial infarcts in rats. J. Nutr. 1959, 69, 325. 